\title{
Computerized screening tools for neurocognitive impairment in patients with HIV infection
}

\author{
Ioana-Catrinel Cercel ${ }^{1 *}$, Șerban Polli ${ }^{1}$, Oana Streinu-Cercel ${ }^{1,2}$, Anca Streinu-Cercel ${ }^{1,2}$, Adrian Streinu-Cercel ${ }^{1,2}$ \\ From The 7th Romanian National HIV/AIDS Congress and The 2nd Central European HIV Forum \\ Sibiu, Romania. 29-31 May 2014
}

Neurocognitive impairment is one the non-infectious comorbidities related to HIV infection [1]. An increasing number of studies have shown the importance of assessing attention, motor, memory and cognitive functions under standardized conditions [2]. We have designed a computerized assessment tool, adapting some well-known methods of neurocognitive evaluation, and we have initiated a pilot study to assess the neurocognitive status of HIV-positive patients and controls.

We assessed patients by applying the Motor Screening Task (MST: providing data on the sensorimotor function or comprehension), the Finger Tapping Test (FTT: motor function, self-directed manual motor speed), the Symbol Digit Test (SDT: divided attention, visual scanning, tracking and motor speed), and the Stroop Task (ST: selective attention and cognitive flexibility). All subjects were evaluated with this computerized set of tests during an appointment with the clinical psychologist. For statistical assessment, the $\mathrm{T}$ score was used.

We assessed $10 \mathrm{HIV}$-positive patients and 15 controls. The median age and standard deviation were $26.5 \pm 11.5$ years (range: $23-54$ ) in the HIV group and $34 \pm 8$ years (range: 25-53) in the control group. The MST scores were $720 \pm 131 \mathrm{~ms}$ and $629 \pm 79 \mathrm{~ms}$ in HIV vs. controls. The FTT scores were $167 \pm 24 \mathrm{~ms}$ and $163 \pm 12 \mathrm{~ms}$ in HIV vs. controls. The SDT scores were $6646 \pm 2905 \mathrm{~ms}$ and $2994 \pm 681 \mathrm{~ms}$ in HIV vs. controls. The ST scores were $689 \pm 92 \mathrm{~ms}, 1602 \pm 1009 \mathrm{~ms}$ and $2045 \pm 580 \mathrm{~ms}$ in the HIV group and $486 \pm 118 \mathrm{~ms}, 1041 \pm 244 \mathrm{~ms}$ and $1023 \pm 163 \mathrm{~ms}$ in the control group. Despite the low number of subjects included in the study, the T score showed a statistically significant difference between the two groups for MST, SDT, ST; no statistically significant difference was observed for FTT between the two groups.

${ }^{1}$ National Institute for Infectious Diseases "Prof. Dr. Matei Balş", Bucharest, Romania

Full list of author information is available at the end of the article
This pilot study has shown that in HIV-positive patients, the cognitive deficit tends to appear earlier than the motor one. Larger studies are needed to confirm these preliminary results and to provide more information on the clinical impact of this computerized tool for neurocognitive screening.

\section{Authors' details}

${ }^{1}$ National Institute for Infectious Diseases "Prof. Dr. Matei Balş", Bucharest, Romania. ${ }^{2}$ Carol Davila University of Medicine and Pharmacy, Bucharest, Romania.

Published: 29 May 2014

\section{References}

1. Guaraldi G: Evolving approaches and resources for clinical practice in the management of HIV infection in the HAART era. GERMS 2011, 1:6-8.

2. Valcour V, Paul R, Chiao S, Wendelken LA, Miller B: Screening for cognitive impairment in human immunodeficiency virus. Clin Infect Dis 2011, 53:836-842.

\section{doi:10.1186/1471-2334-14-S4-O29}

Cite this article as: Cercel et al:: Computerized screening tools for neurocognitive impairment in patients with HIV infection. BMC Infectious Diseases 2014 14(Suppl 4):O29.

\section{Submit your next manuscript to BioMed Central and take full advantage of: \\ - Convenient online submission \\ - Thorough peer review \\ - No space constraints or color figure charges \\ - Immediate publication on acceptance \\ - Inclusion in PubMed, CAS, Scopus and Google Scholar \\ - Research which is freely available for redistribution

